\title{
Thermal and Mechanical Properties of $\mathrm{B}_{4} \mathrm{C}-\mathrm{ZrB}_{2}$ Ceramic
}

\section{Composite}

\author{
Zviad Mestvirishvili, Irakli Bairamashvili, Vakhtang Kvatchadze and Nugzar Rekhviashvili \\ Ivane Javakhishvili Tbilisi State University ElevterAndronikashvili Institute of Physics. 6, Tamarashvil St. 0177 Tbilisi, Georgia
}

\begin{abstract}
B}_{4} \mathrm{C}$ and $\mathrm{B}_{4} \mathrm{C}-\mathrm{ZrB}_{2}(\mathrm{Zr}-3-5 \mathrm{wt} . \%)$ ceramic materials were obtained by the method of hot pressing at temperature range 2,050-2,140 ${ }^{\circ} \mathrm{C}$ and 34-40 MPa pressure, and subject to further thermal treatment at 1,800 ${ }^{\circ} \mathrm{C}$. Physical and mechanical properties of the above composite, the effect of $\mathrm{ZrB}_{2}$ on the process parameters of items formation and on the obtained composite features were studied. Relatively perfect microstructure and optimum physical and mechanical properties are characteristic for $\mathrm{B}_{4} \mathrm{C}-3.7 \% \mathrm{ZrB} 2$ ceramics, the relative density of which equals $100 \%$. Compared to $\mathrm{B}_{4} \mathrm{C}$, it demonstrated $10 \%$ reduced average grain size and $8 \%$ higher fracture toughness; Reduced linear thermal expansion coefficient and mechanical bending strength and doubled thermal conductivity at high temperatures; Increased Young modulus, hardness and compressive strength, which make $363 \mathrm{MPa} ; 30.1 \mathrm{GPa}$ and 3,175 MPa, respectively. When alloying phase $\left(\mathrm{ZrB}_{2}\right)$ content increased to $6.2 \mathrm{wt} . \%$, average grain size growth to $8 \mu \mathrm{m}$, fracture toughness, microhardness and mechanical bending strength decreased and made approximately $2.37 \mathrm{MPa} \sqrt{\mathrm{m}}, 28.2 \mathrm{GPa}$ and $292 \mathrm{MPa}$, respectively.
\end{abstract}

Key words: Boron carbide, alloying, fracture toughness, thermal conductivity, hardness.

\section{Introduction}

Boron carbide finds application in various fields, which is explained by its unique features. Due to high neutron absorption section boron carbide, enriched with ${ }^{10} \mathrm{~B}$ isotope finds application in nuclear engineering, it is used for the production of absorption control rods, burnablepoison control rods and reactor protection system for nuclear power plants. Boron carbide of natural isotopic composition finds similar application.

As a perfect absorber of kinetic energy boron carbide plates are widely used in advanced body armor systems and aircraft armor systems. Boron carbide is used to make fillers, sandblast nozzle, grinding powders and others. In the above areas, the crucial is its hardness HV- $28 \div 40$ GPa [1-4], Young's modulus - 375 $\div 460$ GPa $[1,3-6]$ and bending strength $-280 \div 550[3,6,7]$.

It should be noted that the boron carbide is characterized by low fracture toughness, which,

*Corresponding author: Zviad Mestvirishvili, Ph.D., research fields: ceramic composites, armor ceramics and nuclear power. according to various published sources varies within 1.8-4.3 $\mathrm{MPa} \sqrt{\mathrm{m}}_{\mathrm{m}}$ ranges $[2,3,7]$. Accordingly, the fragility of boron carbide is high and cannot stand both mechanical and thermal impact.

Fracture toughness of the material working in extreme conditions (bearings, ballistic armor plate, planetary mill media, etc.) is the basic parameter of the material. For example, if we consider that the hardness is a measure of the potential ballistic performance of the ceramic, it is possible to conclude that say fracture toughness is a measure of how much of this potential can be realized.

From the viewpoint of fracture ceramics boron carbide occupies the lowest place among other advanced ceramics. Therefore, the research conducted with boron carbide are mostly directed to the improvement of its fracture toughness parameter. Generally precipitation strengthening is used in the efforts to increase crack resistance. For this purpose various quantities of finely dispersed phases of metals, their refractory compounds, ceramic nano-powders and nano-fibers, etc., are doped into boron carbide. 
Production of high cracking resistance and high hardness composite contributes significantly to its successful application as construction materials working under extreme conditions (nuclear engineering, production of armor and etc.).

The objective of the presented work is to obtain dispersion-strengthened $\mathrm{B}_{4} \mathrm{C}-\mathrm{ZrB}_{2}$ composite using the method of hot pressing, which will show improved fracture toughness, compared to $\mathrm{B}_{4} \mathrm{C}$, preserving unique properties of the latter, such as specific weight, hardness, etc.

Such kind of was already obtained earlier $\left(\mathrm{B}_{4} \mathrm{C}-20 \div\right.$ 40 vol.\% $\mathrm{ZrB}_{2}$ ) [8], the parameters of which were as follows: hardness-28.8-30.4 GPa; fracture toughness 6.3-7.0 MPa $\sqrt{\mathrm{m}}$ and bending strength - 325-500 MPa. Addition of 40 vol.\% of $\mathrm{ZrB}_{2}$ raised the material specific weight up to $4 \mathrm{~g} / \mathrm{cm}^{3}$. To our opinion, it follows from the above that to improve the cracking resistance of boron carbide the second doped phase $\left(\mathrm{ZrB}_{2}\right)$ should be as small as possible (up to 5 vol.\%) to avoid substantial changes in the unique features of the material.

Selection of zirconium seems substantially promising for this work, due to its very low neutron absorption section value $\left(\sigma_{\mathrm{Zr}}=0.185\right.$ barn $)$. To the opinion of the authors of [9] in future it would be useful to pass to composite ${ }^{11} \mathrm{~B}_{4} \mathrm{C}-\mathrm{Zr}^{11} \mathrm{~B}_{2}$, enriched with boron-11 isotope $\left(\sigma_{11 \mathrm{~B}}=0.005\right.$ barn $)$, which, as a construction material may find application for working mechanisms in the active zones of the nuclear reactors of the 4-th generation. Beside neutron reflector and moderator it can be antifriction pairs for various friction units, etc.

To obtain the above described ceramics a special hot pressing technology was developed. Specimens of both boron carbide and $\mathrm{B}_{4} \mathrm{C}-\mathrm{ZrB}_{2}$ composite were prepared in high temperature vacuum furnace. Prior to mechanical processing the specimens was subject to thermal treatment to remove thermal stress and for the material homogenization. Microstructure, compression strength and bending strength, young modulus, micro-and macro hardness, thermal expansion coefficient, thermal conductivity temperature dependence and other parameters of the composite were investigated.

\section{Experimental}

\subsection{Powder Production}

For further formation of experimental specimens boron carbide micropowder was used ("H. C. Starck", Grade - HP), the grain sizes of which were as follows: $\mathrm{D}_{50}-2.5 \mu \mathrm{m} ; \mathrm{D}_{90}-6 \mu \mathrm{m} ; \mathrm{D}_{\max }-10 \mu \mathrm{m}$, and, besides, zirconium boride micropowder $\left(\mathrm{D}_{90}-4 \mu \mathrm{m}\right)$ was procured from the chemical reagent plant in Donetsk.

The quantities of the above powders were mixed in such way, that the metal $(\mathrm{Zr})$ doping component of the obtained composite made 3 and 5 wt.\%, which was equivalent to 3.7 and $6.2 \mathrm{wt} . \%$ zirconium diboride. The powders were initially mixed in dry form in a polyethylene container using a turbulent mixer, which was followed by mixing it in ethylic alcohol in a porcelain container, and the obtained suspension was dried in a drying oven $\left(16 \mathrm{~h}, 90-110^{\circ} \mathrm{C}\right)$.

\subsection{Items Formation}

Specimens were made from the obtained composite powder using the method of hot pressing. Table 1 below presents the parameters of the obtained specimens and hot pressing process parameters. Heating and cooling speeds were $50{ }^{\circ} \mathrm{C} / \mathrm{min}$ and 20 ${ }^{\circ} \mathrm{C} / \mathrm{min}$, respectively. Both disk- and cylinder-form specimens were formed in compliance with ASTM, ISO and JIS standards. APB type graphite (Russia) press moulds were used, which were covered with a graphite foil ('SIGRAFLEX' for disk-form specimens) or colloidal graphite (B-1 for cylindrical specimens) to isolate the mould inner surfaces from the composite powder. For thermal stress removal and homogenization the specimens were subject to further thermal treatment in СШВ type vacuum furnace (Russia), (1,800 $\left.{ }^{\circ} \mathrm{C}, \quad 34 \mathrm{~Pa}\right)$. After processing the specimens were subject to processing with diamond 
Table 1 Composite specifications and hot pressing process parameters.

\begin{tabular}{|c|c|c|c|c|c|c|c|}
\hline \multirow{2}{*}{ No. } & \multirow{2}{*}{ Composite } & \multirow{2}{*}{ Zr, wt.\% } & \multirow{2}{*}{$\mathrm{ZrB}_{2}$, wt.\% } & \multirow{2}{*}{$\begin{array}{l}\text { Specimen } \\
\text { dimensions }\end{array}$} & \multicolumn{3}{|c|}{ Process parameters } \\
\hline & & & & & $\mathrm{T},{ }^{\circ} \mathrm{C}$ & $\mathrm{P}, \mathrm{MPa}$ & $\tau, \min$ \\
\hline 1 & BC-d & 0 & 0 & \multirow{3}{*}{$\varnothing 45 \times 1.5 \mathrm{~mm}^{2}$} & 2,140 & 40.0 & 14 \\
\hline 2 & BCZ3-d & 3 & 3.711 & & 2,140 & 40.0 & 10 \\
\hline 3 & BCZ5-d & 5 & 6.185 & & 2,100 & 40.0 & 10 \\
\hline 4 & BC-D & 0 & 0 & \multirow{4}{*}{$\varnothing 70 \times 5 \mathrm{~mm}^{2}$} & 2,130 & 37.0 & 14 \\
\hline 5 & BCZ3-D & 3 & 3.711 & & 2,125 & 37.0 & 8 \\
\hline 6 & BCZ5-D & 5 & 6.185 & & 2,125 & 38.5 & 11 \\
\hline 7 & $\mathrm{BC}-\mathrm{C}$ & 0 & 0 & & 2,100 & 37.0 & 10 \\
\hline 8 & $\mathrm{BCZ3-C}$ & 3 & 3.7 & \multirow{2}{*}{$\varnothing 14 \times 28 \mathrm{~mm}^{2}$} & 2,100 & 37.0 & 14 \\
\hline 9 & $\mathrm{BCZ5-C}$ & 5 & 6.2 & & 2,050 & 34.0 & 14 \\
\hline
\end{tabular}

tools to bring them to the required dimensions. Using a special electric spark machine (type 4531, Russia) specimens $\left(3 \times 4 \times 45 \mathrm{~mm}^{3}\right)$ were cut from the large $(\varnothing$ $70 \times 4 \mathrm{~mm}^{2}$ ) disk-form items for further three-point bending strength testing and for thermal expansion coefficient measurements. Thermal conductivity and thermal mechanical stress were measured using formed cylindrical specimens $\left(\varnothing 14 \times 28 \mathrm{~mm}^{2}\right)$.

\subsection{Material Studies}

Densities of the specimens were measured by the Archimedes method. Relative density was both taken from the published data $\left(\rho-\mathrm{B}_{4} \mathrm{C}=2.52 \mathrm{~g} / \mathrm{cm}^{3}\right)$, and calculated theoretically $\left(\rho-\mathrm{B}_{4} \mathrm{C}-\mathrm{Zr} 3 \%=2.576 \mathrm{~g} / \mathrm{cm}^{3}\right.$; $\left.\rho-\mathrm{B}_{4} \mathrm{C}-\mathrm{Zr} 5 \%=2.615 \mathrm{~g} / \mathrm{cm}^{3}\right)$.

$\mathrm{X}$-ray structural analysis was made using XZG-4A type instrument (Germany).

Ceramography included specimen surface grinding by diamond disk with grain size $125 \div 100 \mu \mathrm{m}$, polishing with $\mathrm{P} 150 \div \mathrm{P} 2000$ type silicon carbide abrasive paper and electrochemical etching for 3-10 sec in $1 \% \mathrm{NaOH}$ water solution at 5-10 V and 200-300 $\mathrm{mA}$ electric power conditions. Polished and etched as above surfaces were subject to microscopic studies using MEIJI TECHNO type IM 7100 inversion metallurgical optical microscope (Japan).

Average and maximal grain sizes were determined by ASTM E-112 and E-930 methods. Microhardness (Berkovich) and Young modulus were measured by SHIMADZU DUH-211S (Japan) instrument both in indentation, and loading and unloading modes, in compliance with ISO-14577 requirements.
Determination of dynamic hardness value was conducted in loading process, using the software of the instrument, while static, or relaxed hardness was determined by measure of indent diagonals by the microscope; Their values averaging was made automatically.

To determine the material elasticity modulus from loading-unloading firstly calculated rigidity as follows:

$$
S=\left(\frac{d P}{d h}\right)_{h=h_{\max }}
$$

which is the tangent line on the unload curve (on the starting point of unload).

Module value calculation was made in automatic mode from equation:

$$
\begin{gathered}
E_{r}=\frac{S}{2} \frac{\sqrt{\pi}}{h_{c} \sqrt{26.43}} \\
\frac{1}{E_{r}}=\frac{1-v_{s}^{2}}{E_{s}}+\frac{1-v_{i}^{2}}{E_{i}} \\
h_{c}=h_{\max }-0.75\left(\frac{P_{\max }}{S}\right)
\end{gathered}
$$

where, $\mathrm{E}_{\mathrm{r}}$ is effective modulus, $\mathrm{i}$ and $\mathrm{s}$ are indices for indenter and material, $v$ and $\mathrm{E}$ are Poisson's ratio and elastic modulus, respectively. Poisson's ratio of the material was assumed equal to 0.18. Additionally, elastic modulus was measured by acoustics pectroscopic method using a non-standard measuring unit (specimen dimensions were $1 \times 3 \times 10 \mathrm{~mm}^{3}$ ).

Bending strength was measured by ASTM C-1161 method, using $3 \times 4 \times 45 \mathrm{~mm}^{3}$ specimens, a three-point measuring method, using ZDM 2.5/91 machine (Germany); specimens were tested perpendicular to pressing direction. Compressive strength was 
measured by ASTM-C-1424 method in cylindrical specimens with H/D ratio 2/1 (Ø $13.5 \times 27 \mathrm{~mm}^{2}$, alternative form specimens for ceramics studies). The samples were tested in parallel to the direction for pressing.

Thermal conductivity was determined in $\varnothing 13 \times$ $26 \mathrm{~mm}^{2}$ cylindrical specimens in $300-1,000 \mathrm{~K}$ temperature range in a measuring unit, described inarticles $[10,11]$ (absolute stationery method).

Hardness (HV) and fracture toughness was determined under loading of $5 \mathrm{~kg}$ in facility, type ТП-7P-1 (Russia) and calculated using standard equations (ASTM C 1327-03, JIS R 1607 [12]):

$$
\begin{aligned}
& H V=1.854 P / d^{2} \\
& K_{I C}=0.026 \frac{\sqrt{E P} d}{\sqrt[2]{C^{3}}}
\end{aligned}
$$

30 indents were made on the polished surfaces of each specimen. Prints and cracks were measured by optical microscope (IM 7100).

\section{Results and Discussions}

Table 2 presents results of the conducted specimen studies.

Out of large disk-form items those, made of BCZ5-D composite show low relative density, compared to other two (BC-D and $\left.\mathrm{BCZ}_{3}-\mathrm{D}\right)$. Triple eutectics, $\mathrm{ZrB}_{2}-\mathrm{B}_{4} \mathrm{C}-\mathrm{C} \quad(\mathrm{Zr}-11 \%, \mathrm{~B}-66 \%, \mathrm{C}-23 \%$ [13]) is observed on the above composition item surface between its constituent phases and the graphite foil, which melted to temperature $2,125{ }^{\circ} \mathrm{C}$ and pressure 38.5 MPa. In the result of small quantities of liquid gases formation recrystallization was observed, and expanded the homogeneity region and grain size rose up to $47 \mu \mathrm{m}$ (Fig. 1b, maximal grain size). The Figure shows that $\mathrm{ZrB}_{2}$ phase almost disappeared from the specimen surface.

Average grain size range of BCZ3-D composite is lower than that of BC-D composition, while the maximum grain size significantly increased, compared to $\mathrm{BC}$-D. It means that $\mathrm{CZ}_{3}-\mathrm{D}$ composite homogeneity region substantially expanded. Decrease of average grain size is the result of $\mathrm{ZrB}_{2}$ phase addition as recrystallization inhibitor phase. Besides, $\mathrm{ZrB}_{2}$ phase also has its effect on the sintering duration decrease.

It should be noted that the maximum grain size in $\mathrm{D}$ geometry items is generally high, because of which cylindrical items were formed at relatively low temperature. In case of the temperature reduction we observe slight reduction of both average and maximum grain sizes.

\begin{tabular}{|c|c|c|c|c|c|c|}
\hline \multirow{2}{*}{ No. } & \multirow{2}{*}{\multicolumn{2}{|c|}{ Physical and mechanical properties }} & \multicolumn{4}{|c|}{ Composite features and composition } \\
\hline & & & Specimen form & $\mathrm{BC}$ & $\mathrm{BCZ3}$ & $\mathrm{BCZ5}$ \\
\hline \multirow{2}{*}{1} & \multirow{2}{*}{\multicolumn{2}{|c|}{ Relative density, $\%$}} & $\mathrm{D}$ & 99.2 & 99.3 & 97.7 \\
\hline & & & $\mathrm{C}$ & 99.7 & 100.0 & 99.5 \\
\hline \multirow{4}{*}{2} & \multirow{4}{*}{ Grain size, $\mu \mathrm{m}$} & $\mathrm{D}_{\text {aver. }}$ & \multirow{2}{*}{$\mathrm{D}$} & 5.0 & 4.5 & 8.0 \\
\hline & & $\mathrm{D}_{\max }$ & & 21 & 30 & 47 \\
\hline & & $\mathrm{D}_{\text {aver. }}$ & \multirow{2}{*}{$\mathrm{C}$} & 5.0 & 5.0 & 7.0 \\
\hline & & $\mathrm{D}_{\max }$ & & 17 & 24 & 40 \\
\hline 3 & Thermal expansion coefficient, $10^{-6} / \mathrm{K}$ & $(773 \mathrm{~K})$ & $\mathrm{D}$ & 3.94 & 3.88 & 3.81 \\
\hline \multirow{2}{*}{4} & \multirow{2}{*}{ Thermal conductivity, $\mathrm{W} \cdot \mathrm{m} / \mathrm{K}$} & $300 \mathrm{~K}$ & \multirow{2}{*}{$\mathrm{C}$} & 38.5 & 37.5 & 37.5 \\
\hline & & $1,000 \mathrm{~K}$ & & 6.3 & 11.8 & 11.7 \\
\hline 5 & Bending strength, $\mathrm{MPa}$ & & $\mathrm{D}$ & 486 & 287 & 292 \\
\hline 6 & Compressive strength, $\mathrm{MPa}$ & & $\mathrm{C}$ & 3,080 & 3,175 & 3,875 \\
\hline \multirow{2}{*}{7} & \multirow{2}{*}{ Microhardness (Berkovich) $1 \mathrm{~N}, \mathrm{GPa}$} & Dynamic & \multirow{2}{*}{$\mathrm{D}$} & 14.8 & 14.9 & 14.6 \\
\hline & & Static & & 29.4 & 29.9 & 28.2 \\
\hline 8 & Hardness HV5, GPa & & $\mathrm{D}$ & 27.5 & 30.1 & 29.6 \\
\hline 9 & Young modulus E, GPa & & $\mathrm{D}$ & 358.5 & 363.0 & 366.5 \\
\hline 10 & Fracture toughness, $\mathrm{K}_{\mathrm{IC}} \mathrm{MPa} \sqrt{\mathrm{m}}$ & & $\mathrm{D}$ & 2.56 & 2.76 & 2.37 \\
\hline
\end{tabular}

Table 2 Physical and mechanical properties of the composites. 


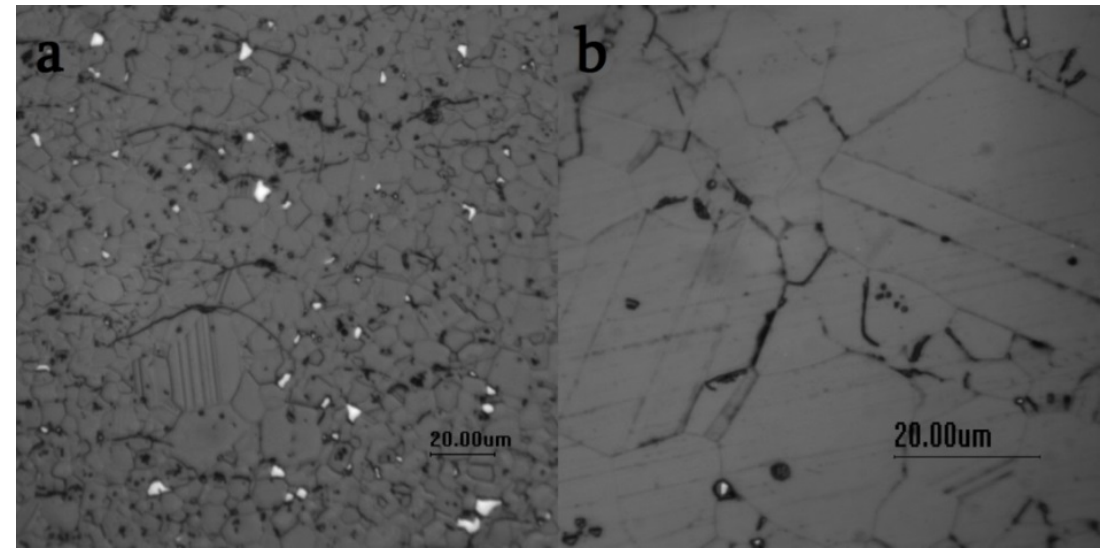

Fig. 1 Optical microphotography of (a) $B C Z_{3}-D$ and (b) $B C Z_{5}-D$ composites.

Relative density of C-geometry items makes almost $100 \%$, here also density in composite BCZ3is the highest.

Bending strengths of both compositions of $\mathrm{BCZ}$ are almost similar, however, their values are much lower than that in $\mathrm{B}_{4} \mathrm{C}\left(\mathrm{BCZ}_{3}-287 \mathrm{MPa}, \mathrm{BCZ} 5-292 \mathrm{MPa}\right.$, BC-486 MPa). Boron carbide bending strength decrease due to the addition of zirconium diboride is known [8], due to the impact of the second phase-as low bending strength phase. Growth of the grain sizes and extension of the homogeneity region also decreases mechanical bending strength [14]. Decrease of bending strength, as a result of the grain size growth is, probably caused by the decrease of intercrystalline fracture share and growth of the transcrystalline fracture share. Such phenomenon was observed in various composites (dispersion-strengthened and fiber composites) [15]. However, according to some results in single-phase materials, when we insert other phases the transcrystalline fracture share increases, despite the fact, whether the grain size grows or not in the basic phase, i.e. of the matrix $[15,16]$. We believe that substantial decrease of $\mathrm{BCZ}$ composite bending strength depends greatly on twins' formation in the grown grains (Fig. 1). Twin formation is the basic defect of boron carbide microstructure. Such grains due to weak bonds break to more parts between the layers during bending.

The grain size effect on the compressive strength is of comparatively lower importance [17]. Boron carbide compressive strength increases with alloying, and, in particular, in $\mathrm{BCZ}_{5}$ composite, where beside the alloying element quantity (both, high bending strength material quantity growth, and the material plastic component growth) a second factor arises, i.e., interphase bond strength grow, which is caused by triple eutectics temperature proximity.

Static and dynamic microhardness increases in $\mathrm{BCZ}_{3}$ composite and decreases in $\mathrm{BCZ}_{5}$ composite. Fig. 2 presents microhardness indentations on the polished surface of BCZ5 composite: boron carbide phase microhardness (Fig. 2a) equals $30.4 \mathrm{GPa}$, which is higher than $\mathrm{BC}$ composition microhardness. $\mathrm{ZrB}_{2}$ phase (Fig. 2b) microhardness is $23.4 \mathrm{GPa}$; which stipulates $\mathrm{BCZ}_{5}$ composite average hardness low value compared to the $\mathrm{BC}$ composition hardness.

In $\mathrm{BCZ}_{3}$ composite $\mathrm{ZrB}_{2}$ phase content is lower, than in $\mathrm{BCZ}_{5}$ composite, and low value of the above phase hardness does not affect greatly on the average hardness value. That is why average hardness of $\mathrm{BCZ}_{3}$ composite is higher, than that of $\mathrm{BC}$ composite hardness. Thus, improving of microhardness (aver. $30.1 \mathrm{GPa}$ ) only low solubility of $\mathrm{ZrB}_{2}$ in $\mathrm{B}_{4} \mathrm{C}$ [13] should be explained.

Young modulus of boron carbide grows with the alloying growth. Young modulus of boron carbide phase rose from $358.5 \mathrm{GPa}$ (Table 2, BC composition) up to $364 \mathrm{GPa}$ in $\mathrm{BCZ}_{5}$ composite (young modulus of $\mathrm{B}_{4} \mathrm{C}$ phase, shown in Fig. 2a). This phenomenon should be explained by the solubility of zirconium in boron 


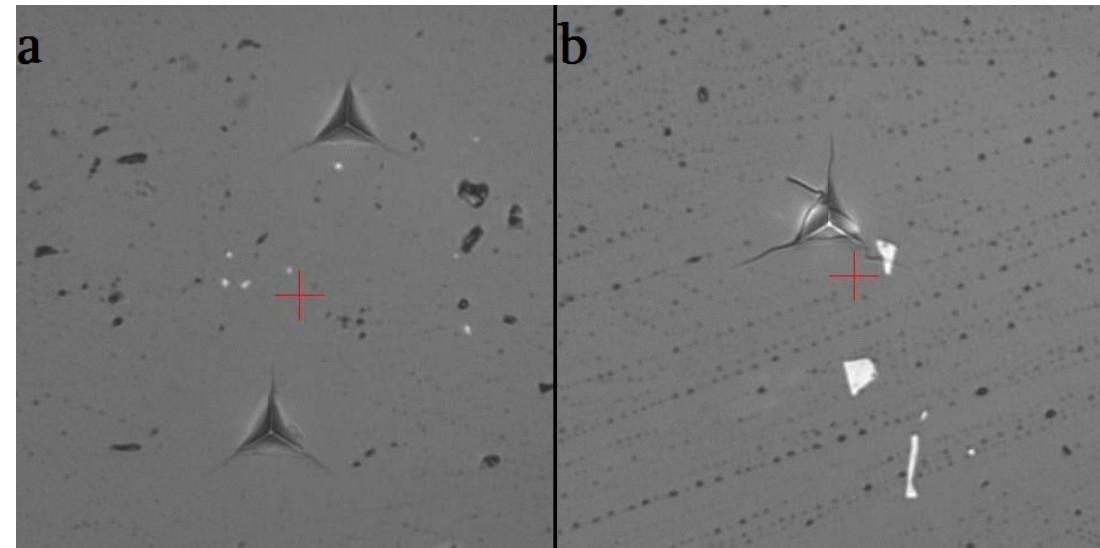

Fig. 2 Microhardness indentations inBCZ $Z_{5}-\mathrm{D}$ composite.

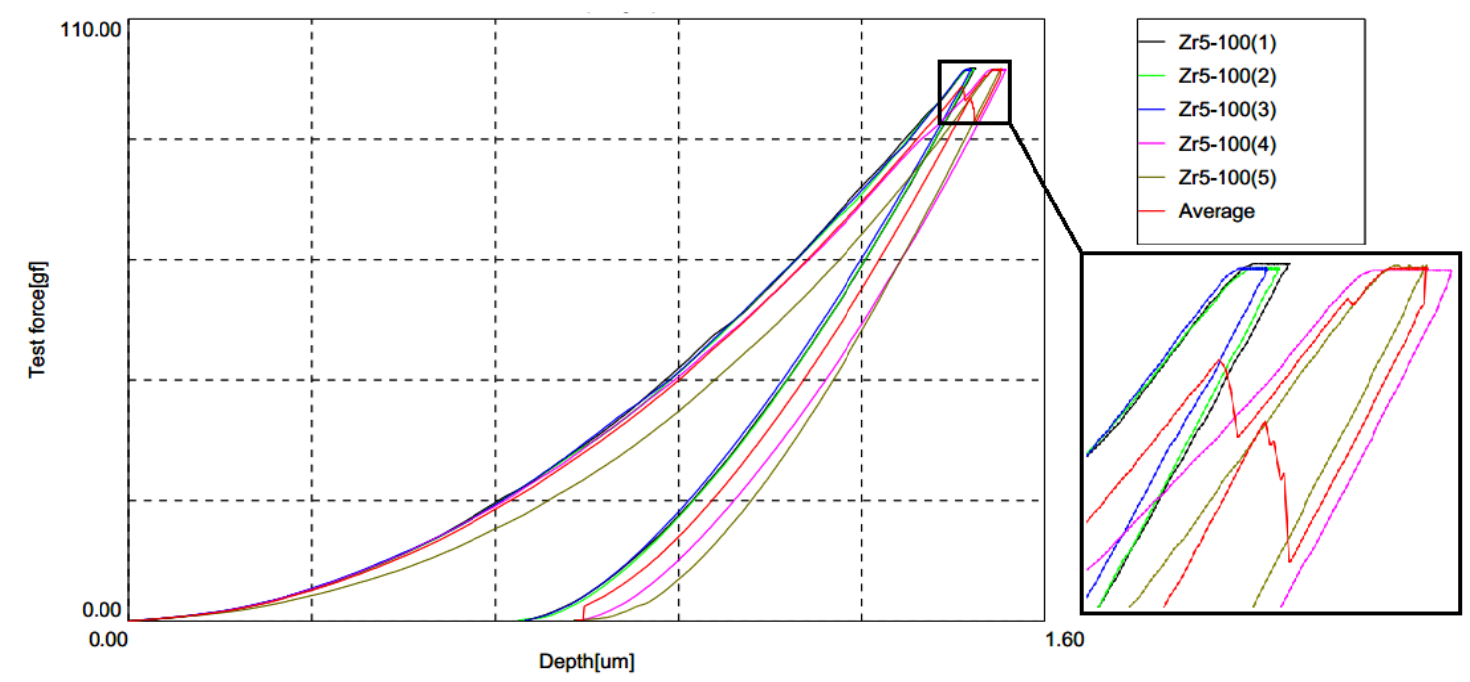

Fig. $3 \mathrm{BCZ}_{5}$ composite loading-indentation depth dependence.

carbide: in BCZ5 composite Young modulus value of $\mathrm{ZrB}_{2}$ phase is $377 \mathrm{GPa}$ (Fig. $2 \mathrm{~b}$, indentation in $\mathrm{ZrB}_{2}$ phase), however, average value of Young modulus in this composite equals $366.5 \mathrm{GPa}$.

Fig 3 shows graphically load-indentation depth dependence, which is recorded by the instrument program. The first three curves belong to boron carbide phase. While the last to $-\mathrm{ZrB}_{2}$. The graph shows differences in the curve characters, which can be explained with the differences in hardness and Young modulus.

The picture of microhardness changes is similar to that of microhardness changes: substantially increases within the solubility ranges, however, starts to decrease again with the growing $\mathrm{ZrB}_{2}$ content.

Fracture toughness increased by $8 \%$ in $\mathrm{BCZ}_{3}$ composite, while in $\mathrm{BCZ}_{5}$ composite it decreased similarly. Crack resistance increase in $\mathrm{BCZ}_{3}$ composite is explained by the decrease in the grain size compared to $\mathrm{B}_{4} \mathrm{C}$ (average grain size decreased by $10 \%$ ) [14]. Existence of high crack resistance phase in the composite was an additional factor.

Fracture toughness decrease in $\mathrm{BCZ}_{5}$ composite is explained by the grain growth. Mainly, magistral cracks propagated in highly fragile large grains of boron carbide. In this case influence of crack arrest factors, such as pores, vacancies, small size grains of the second phase, located at the boundaries of boron carbide grains are weak that is why crack resistance decreases.

Fig. 4 shows temperature dependence of thermal conductivity. At temperatures, close to room temperature, 


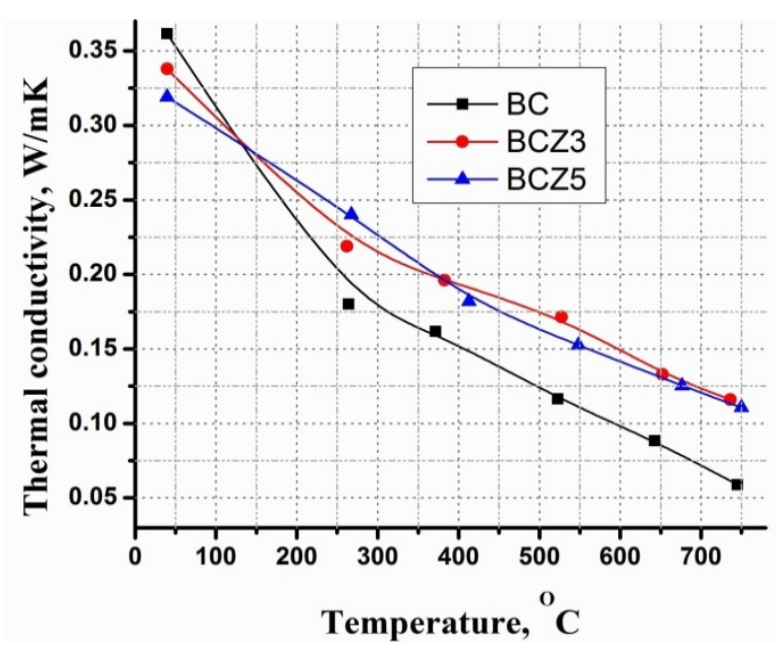

Fig. 4 Temperature dependence of thermal conductivity.

and in particular, at $40{ }^{\circ} \mathrm{C}$ trend towards thermal conductivity decrease is observed with the increase of the quantity of alloying element $\left(\mathrm{ZrB}_{2}\right)$; however, with the temperature rise $\left(>150^{\circ} \mathrm{C}\right)$ we observe the opposite picture: thermal conductivity of the composites substantially exceeds that of $\mathrm{BC}$ composition. For example, at $750{ }^{\circ} \mathrm{C}$ thermal conductivity of boron carbide, alloyed with $\mathrm{ZrB}_{2}$ is almost twice that of the unalloyed boron carbide.

According to known Debye equation for phonon thermal conductivity [18]:

$$
\lambda=\left(\frac{1}{3}\right) C_{V} v l
$$

where, $\lambda$ is thermal conductivity coefficient, $C_{v}$ is heat capacity of unit volume of the material inconstant-volume conditions, $v$ is average speed of sound propagation, 1 is phonon free path value. Free path for every mechanism of phonon scattering, $l_{i}$ is calculated separately, and in result, Debye equation will look as follows:

$$
l=\left(\Sigma_{i} l_{i}^{-1}\right)^{-1}
$$

It is possible to evaluate the three mechanisms of scattering at $40{ }^{\circ} \mathrm{C}$ : Phonon-phonon interaction $1_{\mathrm{Ph}}$; phonon scattering on defects $l_{D}$ and at the grain boundary $l_{\mathrm{GB}}$. This implies the possibility to pass for the first of the above parameters for all the three materials equally. Thus $l_{\mathrm{D}}$ and $1_{\mathrm{GB}}$ are still to be determined. It is knows, that $\mathrm{l}_{\mathrm{GB}} \sim \sqrt{\mathrm{d}}[18]$, where, $\mathrm{d}$ is the grain cross section, and thermal conductivity should increase with the grain size growing [19], which we do not observe considering the maximal grain size values, given in the presented Table. If we review the situation with the average grain sizes, we will observe mutually exclusive results for the studied composites. In particular, in the considered situation, experimental results imply $\left(<150^{\circ} \mathrm{C}\right)$, that the mechanism of phonon scattering on defects is the most important one. These defects are the result of doping elements in the material, and as Fig. 4 shows that thermal conductivity decreases respectively with the alloying elements quantity growth(it is known, that $1_{D}^{-1} \sim C_{D}[18]$, where, $C_{D}-$ concentration of point defects). With further temperature rise both observed scattering mechanisms weaken gradually, and in the end become negligible [18]. To our opinion, at relatively high temperatures ( $>$ $\left.150{ }^{\circ} \mathrm{C}\right)$ growth of thermal conductivity of the composites is caused by those nonlocalized electrons, which appear in the material in the result of the diboride phase introduction into it. They strengthen covalent bonds, and thus, raise thermal conductivity.

In case of passing to the investigation of ${ }^{11} \mathrm{~B}_{4} \mathrm{C}-\mathrm{Zr}^{11} \mathrm{~B}_{2}$ composite in future the results obtained here on high temperature thermal conductivity increase will become still more important [9], if we consider the fact that enrichment with ${ }^{11} \mathrm{~B}$ isotope results in the undesired decrease of the boron carbide thermal conductivity. $[10,20]$. We believe, that the result of alloying the above composite with zirconium diboride in its importance will exceed the "undesirable" effect of ${ }^{11} \mathrm{~B}$ on thermal conductivity.

\section{Conclusions}

$\mathrm{B}_{4} \mathrm{C}$ and $\mathrm{B}_{4} \mathrm{C}-\mathrm{ZrB}_{2}$ construction ceramics was obtained with high relative specific weight. Theoretical density of compositeBCZ3 (3.711 wt.\% $\mathrm{ZrB}_{2}$ ) was obtained in temperature $2,100{ }^{\circ} \mathrm{C}$ and pressure $37 \mathrm{MPa}$ process conditions. The above composite differs from the other ones by relatively low values of average grain sizes. Besides, alloying negative influence on the 
homogeneity of the grain sizes should alsobe mentioned.

In the result of alloying bending strength of the composites decreased substantially and madefrom 486 $\mathrm{MPa}(\mathrm{BC})$,down to $287 \mathrm{MPa}\left(\mathrm{BCZ}_{3}\right)$ and $292 \mathrm{MPa}$ $\left(\mathrm{BCZ}_{5}\right)$, which can be explained by the grain growth and grain defects: twins formation. Recrystallized grains cause decrease of the intercrystalline fracture shareand growth of the transcrystalline fracture share.

Obtained ceramics show high mechanical compressive strength, especially alloyed items, in which strength value reached $3875 \mathrm{MPa}\left(\mathrm{BCZ}_{5}\right)$. These conditions, both the material plastic component, and interphase bond strength improve, in itself were caused by triple eutectics temperature proximity.

In the result of alloying Young modulus, as well as micro- and microhardnesses grew. Hardness value is especially impressive, when $\mathrm{ZrB}_{2}$ content in boron carbide is at the solubility limiting value. If the alloy addition is more than solubility limit - in case of alloying growth, hardness tends to decrease.

The thermal conductivity of obtained composites is higher than that of $\mathrm{B}_{4} \mathrm{C}$ at high temperatures. Probably, in alloying, when nonlocalized electrons appear in the material covalent bonds strengthened and in result phonon thermal conductivity strengthened too.

As concerns fracture toughness, it increased from 2.56 $\mathrm{MPa} \sqrt{\mathrm{m}}(\mathrm{BC})$ up to $2.76 \mathrm{MPa} \sqrt{\mathrm{m}}\left(\mathrm{BCZ}_{3}\right)$. Crack resistance increase is caused by both alloying proper (doping high crack resistant phases), and by the decrease of grain sizes.

And finally, $\mathrm{BCZ}_{3}$ composite showed optimal physical, mechanical and thermal parameters (in particular, its simultaneously growing fracture toughness, hardness and high temperature thermal conductivity values). Works should be undertaken to provide wide application ofBCZ3 and to develop and arrange experimental production of this novel promising material.

\section{Acknowledgements}

Authors express their gratitude to the colleagues from the Georgian Tech. University and Ilia Vekua Sokhumi Institute of Physics and Technology, who assisted in measuring some features of the obtained ceramics.

This work was supported by GNSF grant AR/206/6-130/12.

\section{References}

[1] Nino, A., Tanaka, A., Sugiyama, S. and Taimatsu, H. 2010. "Indentation Size Effect for the Hardness of Refractory Carbides." Materials Transactions 51 (9): 1621-6.

[2] Cengiz, M., Yavas, B., Celik, Y., Goller, G., Yucel, O. and Sahin, F. C. 2014. "Spark Plasma Sintering of Boron Carbide Ceramics Using Different Sample Geometries and Dimensions." Acta Physica Polonica A 125 (2): 260-2.

[3] Huang, S. G., Vanmeensel, K., Malek, O. J. A., Biest, O. Van der. and Vleugels, J. 2011. "Microstructure and Mechanical Properties of Pulsed Electric Current Sintered $\mathrm{B}_{4} \mathrm{C}-\mathrm{TiB}_{2} \quad$ Composites." Materials Science and Engineering A 528: 1302-9.

[4] Moshtaghioun, B. M., Ortiz, A., García, D. G. and Rodríguez, A. D. 2013. "Toughening of Super-Hard Ultra-Fine Grained $\mathrm{B}_{4} \mathrm{C}$ Densified by Spark-Plasma Sintering via SiC Addition." Journal of the European Ceramic Society 33: 1395-401.

[5] Prokhorov, V., Perfilov, S., Useinov, A., Veprincev, K., Gnidash, C. and Kuftyrev, R. 2013. "Determination with Integral Ultrasonic Method and Local Force Microscopy Method of Elastic Properties of $\mathrm{B}_{4} \mathrm{C}$ Ceramics Prepared by Hot Pressing." Machines, Technologies, Materials. 12: 21-3.

[6] Jiang, D. L. 2012. "Boron Carbide Ceramics Prepared by Gelcasting and Pressureless Sintering." Journal of the Australian Ceramic Society 48 (1): 122-7.

[7] Kim, K. H., Chae, J. H., Park, J. S., Ahn, J. P. and Shim, K. B. 2009. "Sintering Behavior and Mechanical Properties of $\mathrm{B}_{4} \mathrm{C}$ Ceramics Fabricated by Spark Plasma Sintering." Journal of Ceramic Processing Research 10 (6): 716-20.

[8] Han, W.-B., Gao, J.-X., Zhang, J.-H. and Yu, J.-L. 2013. "Microstructure and Properties of $\mathrm{B}_{4} \mathrm{C}-\mathrm{ZrB}_{2}$ Ceramic Composites." International Journal of Engineering and Innovative Technology 3 (1): 163-6.

[9] Bairamashvili, I. A., Galustashvili, M. V., Jobava, J. Sh.,V. Kvatchadze, G. and Mestvirishvili, Z. Z. 2013. "Composite Ceramics Based on Boron Carbide Enriched in Isotope ${ }^{11} \mathrm{~B}$ as a Promising Radiation Resistant Structural Material." Nano Studies 8: 305-10.

[10] Karumidze, G. S., Kekelidze, L. I. and Shengelia, L. A. 1996. "Coefficient of Heat Conductivity of Boron Carbide with Different Content of the Isotope ${ }^{10}(\mathrm{~B})$ " Physics and 
Technology of Semiconductors 30 (10): 1761-6.

[11] Бокучава, Г. В., Карумидзе, Г. С. and Широков, Б. М.. 2008. "High Temperature Thermoelectric Generator." Aviation and Space Engineering and Technology. 3 (50): 75-8.

[12] "Testing Methods For Fracture Toughness Of High Performance Ceramics." Japanese Standards Association Publications. Japanese Industrial Standard No. JIS R 1607: 1995

[13] Rudy, E. and Windisch, St. "Ternary Phase Equilibria in Transition Metal-Boron-Carbon-Silicon Systems.” Part II. Ternary systems, Volume XIII. Phase Diagrams of The Systems Ti-B-C, Zr-B-C and Hf-B-C, 18-19.

[14] Barick, P., Jana, D. C. and Thiyagarajan, N. 2013. "Effect of Particle Size on the Mechanical Properties of Reaction Bonded Boron Carbide Ceramics." Ceramics International 39 (1): 763-70.

[15] Rice, R. W. 1996. Ceramic Fracture Mode - Intergranular vs. Transgranular Fracture. Ceramic Transections, 64: Fractography of glasses and Ceramics III (JR Varner, VD
Frechette, and GD Quinn, eds). Am. Cer. Soc. Westerville, $\mathrm{OH}, 1-53$.

[16] Baek, Y. K. and Kim, C. H. 1989 "The Effect of Whisker Length on the Mechanical Properties of Alumina SiC Whisker Composites. "Journal of Materials Science 24: 1589-93.

[17] Rezaie, A., Fahrenholtz, W. G. and Hilmas, G. E. 2007. "Effect of Hot Pressing Time and Temperature on the Microstructure and Mechanical Properties of ZrB2-SiC." Journal of Materials Science 42 (8): 2735-44.

[18] Klemens, P. G. and Gell, M. 1998. "Thermal Conductivity of Thermal Barrier Coatings." Materials Science and Engineering A 245 (2): 143-9.

[19] В. Д. Рисованый, А. В. Захаров, Е. П. Клочков, В. Б. Пономаренко, Е. М. Муралева and Т. М. Гусева. 2012. "Consume Materials of the Management and Protection of Nuclear Reactors." Ulyanovsk, 90-101.

[20] Nishi, Y., Arita, Y., Matsui, T. and Nagasaki, T. 2002. "Isotope Effects on Thermal Conductivity of Boron Carbide.” J. Nucl. Sc. and Tech. 39 (4): 391-4. 